\title{
La clase media no tiene auto
}

Wilmer Iván CLOUD MIRAVAL

A raíz del informe del BID (Banco Interamericano de Desarrollo), indicando que el $70 \%$ de la población Peruana pertenece a la clase media, cifra para muchos exagerada, se cuestionaron los parámetros utilizados, se propusieron otros, y vaya que surgieron parámetros, como la propuesta de que para ser considerado de "clase media" se debe tener auto. En la presente trataremos de explicar el significado de "clase media, su importancia y compararla con otras realidades.

En Junio del 2013 el BID emitió un informe, por el cual indicaba que el 70\% de la población peruana pertenece a la clase media, disgregándola en $50 \%$ clase media consolidada y $20 \%$ clase media emergente. Estas cifras fueron materia de discusión nacional e internacional, pues de ser correctas indicarían un considerable crecimiento y consolidación de la economía Peruana.

El origen de estas cifras surgen de la afirmación del FMI (Fondo Monetario Internacional), de que el Perú tiene "ingresos medios", información que fue considerada por el INEI (Instituto Nacional de Estadística e Informática), como base para sus estudios..

El FMI nos coloca en una economía de "ingresos medios", usando la siguiente metodología:

- Considera el PBI per cápita a valores de paridad de poder adquisitivo (PPA). Para explicar la diferencia entre "ingreso nominal" e Ingreso a poder adquisitivo, nos valdremos del siguiente ejemplo; la capacidad de compra de US\$ 100.00 en el Perú, no es el mismo que en USA, en el Perú con US\$ 100.00 en promedio se puede comprar más de lo que se compraría en USA; En consecuencia: El poder adquisitivo varía entre los países, y si se desea comparar una economía con la otra, también hay que considerar las variaciones en su capacidad de compra, en ese sentido el PBI ajustado a valor adquisitivo, es una metodología aceptada mundialmente y del cual no existe mayor discusión.

- Luego el FMI lista las economías sobre las que lleva un registro, las economías que hay en el mundo y las que analiza el FMI son prácticamente 
las mismas (180 economías según el FMI para el 2013), por lo que es representativa para cualquier análisis.

- Como tercer paso ordena las economías de acuerdo a su ingreso per cápita, teniendo por ejemplo para el 2013 el país que tiene el mayor ingreso per cápita es "Catar", con un ingreso per cápita anual de US\$ 105,091 al año, y el más bajo es "La República Democrática del Congo", donde el ingreso per cápita anual es US\$ 364 al año, sorprende las diferencias mundiales....

- De las 180 economías, identifica la media, considerando para el 2013 la media mundial igual a US\$9,143 (coincidentemente es el PBI per cápita de China).

- Finalmente agrupa las economías en rangos, considerando economías de ingreso "muy alto", "alto", "medio alto", "medio", "medio bajo", "bajo", "muy bajo", la gráfica infra nos da una apreciación visual de cómo el FMI agrupa las economías según su ingreso per cápita.

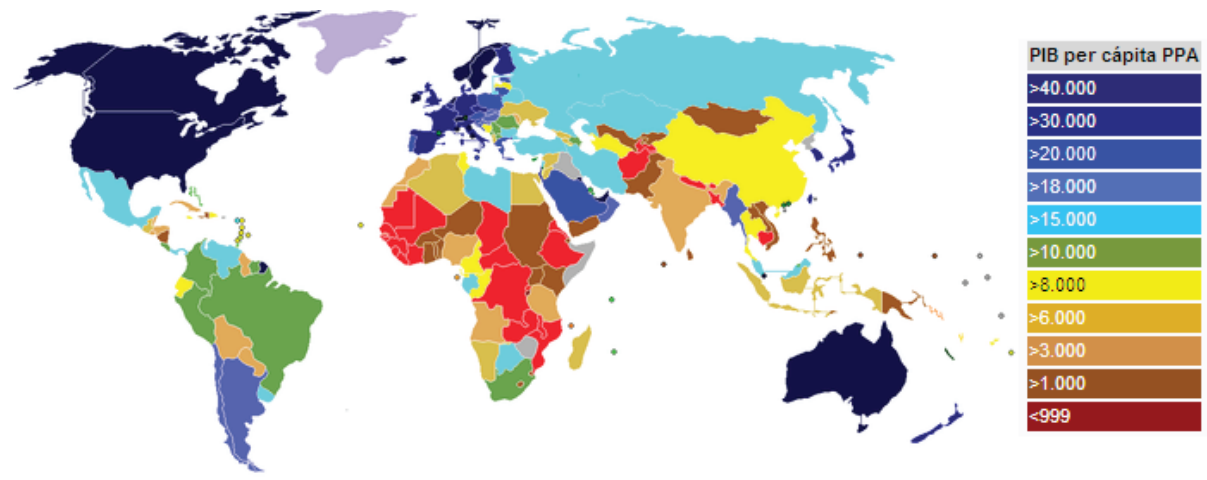

Para estos efectos vale mencionar que un país es considerado desarrollado cuando ha sobrepasado los US\$20,000 anuales per cápita.

El Perú en el 2013 ocupa el puesto $\mathrm{N}^{\circ} 79$ (11 puestos sobre la media), con un ingreso de US\$11,403 al año (más de US\$2,000 sobre la media), es decir por posición y por ingreso le corresponde ser una economía de "ingresos medios". Hasta aquí la metodología del FMI es clara y transparente.

\section{Entonces, ¿Dónde está la controversia?}

La controversia surge de la comparación entre un resultado estadístico (ingreso medio), y un significado de concepto de "clase media", pues para el FMI y el BID es un resultado estadístico, y así lo interpreta el INEI, pues toma 
como referencia la clasificación del FMI, concluyendo sobre esta base de clasificación que el $70 \%$ de la población peruana tiene ingresos medios, por lo que colocándolo en un contexto mundial, el $70 \%$ de la población peruana tiene ingresos equivalentes a los que el FMI consideraría ingresos de nivel medio.

A esto hay que sumarle el hecho que la economía peruana tiene mucha informalidad, datos que el INEI no puede medir con exactitud, ejemplo el INEI puede medir cuánto gana un médico (dado que tiene ingresos por planilla, etc), pero le resulta complicado medir cuántos son y cuánto ganan los comerciantes de Gamarra, la Parada, etc, donde seguramente hay muchos emprendedores que ganan más que algunos médicos.

Sin embargo, la clasificación anterior dista de lo que las empresas investigadoras de mercados, consideran "clase media", pues para sus consideraciones la "clase media", debe tener ciertos requisitos de ingresos, y acceso a ciertos bienes y servicios (estos varían de acuerdo a cada empresa), como por ejemplo agua, desagüe (cantidad de baños), sistema de salud, internet, teléfono, educación de calidad, lavadora y otros electrodomésticos, e inclusive la referencia al título de nuestro artículo, y es que para muchos la clase media debe tener auto.

Ergo, nos encontramos con dos formas de entender un concepto, paradójicamente ambos totalmente válidos, por un lado un análisis netamente estadístico, y por otro, la definición de un concepto de valor o apreciación.

\section{Tratando de entender las razones}

En nuestro acervo cultural, usos y costumbres, entendemos por "clase media", aquella que tiene acceso a un nivel de vida "acomodado", determinado por la tenencia de ciertos atributos y acceso a determinados servicios, en ese sentido, el informe del BID e INEI nos puede sonar exagerado.

Por otro lado, tanto en el BID como en el INEI existen profesionales de nivel, que tienen sus razones para sustentar sus afirmaciones, es más estadísticamente están sustentadas.

En este orden de ideas, las razones por las que el INEI y el BID, redefinieron (por llamarlo de algún modo), el concepto de "clase media", seria por razones de lo que llamaremos "marketing de las estadísticas", pues el mostrarnos como un país con una "clase media", con porcentajes altos es interesante, dado que funcionan como mecanismos de empuje, por ejemplo, si cualquier transnacional de servicios, industria, etc, ve que el Perú tiene una clase media considerable, en un país con más de 30 millones de habitantes, considerará seriamente ingresar al mercado peruano, esto conlleva inversión, empleo de 
calidad, convirtiéndose en un "círculo virtuoso", de desarrollo, al final las cifras pueden terminar alimentándose a sí mismas, por ello probablemente otras instituciones símiles al INEI han procedido de la misma forma (buscar su mejor estadística), esto lo ha hecho Chile por muchos años, esto es el equivalente a publicitar las mejores cifras de un país. Ojo la publicidad tiene muchas caras, se puede publicitar la gastronomía, algunos destinos, y también es perfectamente válido, publicitar los logros económicos, o sus mejores estadísticas (marketing de las estadísticas). Probablemente por un buen manejo de marketing de sus evidentes logros, Chile es una economía que está dando que hablar en el mundo, es miembro de la OCDE (Organización para la Cooperación y el Desarrollo Económico), también conocida como: "el club de los países desarrollados", de igual forma Chile es candidato fijo a ser considerado un país desarrollado el 2014 ó 2015, esto obviamente conlleva una serie de beneficios, como por ejemplo USA ha considerado que desde el 2014, los Chilenos podrán ingresar a USA sin necesidad de Visa. Por el lado Peruano, las cosas también se muestran interesantes, pues según el FMI para el 2018 tendremos un per cápita de US\$ 15,684 la OCDE está mirando con buenos ojos la economía peruana, y ha tenido un acercamiento evidente, considerando un posible ingreso (en un futuro no muy lejano), como miembro, por otro lado la Unión Europea a solicitud de España estudia la posibilidad de que los Peruanos puedan ingresar a Europa sin necesidad de Visa (solo para periodos cortos de estadía), probablemente encontremos aquí las razones del INEI y el BID, para mostrar la mejor cara de la estadística (publicitar nuestros logros).

Qué es ¿Clase Media?. Las palabras y conceptos pueden tener significados ambiguos, en ese sentido "clase media", como significado estadístico puede diferir del clásico, personas o familias "acomodadas".

El dilema surge cuando se quiere explicar, que es una persona "acomodada", nos valdremos de algunas comparaciones internacionales, por ejemplo en Japón solo la clase alta acude a un restaurant más de dos veces al mes, la "clase media", por lo general va al restaurant cuando tiene algo importante que celebrar, en el Perú la cosa es distinta.

Respecto a nuestro titular, nos llama la atención, una clase media que no posea auto (evidentemente el $70 \%$ de la población no posee auto), pero probablemente nos llame también la atención si decimos que en Nueva York, gran parte de la clase media, tampoco tiene auto (especialmente la que vive en el mítico Manhattan), lo cual indica cuan diverso puede ser el criterio para medir las cosas, pero un buen porcentaje de los habitantes de Manhattan donde vive gran parte de la clase media de Nueva York, no poseen auto, y no es porque no lo puedan comprar, sino porque es incómodo, pues en Manhattan la gente se moviliza en Taxi o en el Metro (que por cierto es uno de los mejores del 
mundo), tener auto y movilizarse en ello sería demasiado incómodo y caro, pues no hay sitios donde parquear, y si los hay son demasiado caros, tal es así que tener auto o no tenerlo, no define el estatus socio económico.

Finalmente, decir que nuestra clase media, comparativamente, no será la envidia del mundo, pero si es evidente, que hemos vuelto a tener clase media, solo queda esperar que esta vez sea cuesta arriba, tanto en cantidad y calidad, y lo más importante, mantenerla y hacerla crecer no solo es responsabilidad del estado, sino que cada cual, en su puesto contribuya a ello, así que a dar nuestro mejor esfuerzo, buscarle el lado positivo de las cosas, dar más y exigir menos, y así en algún momento podamos tener una "clase media" con auto y mucho más.

\section{BIBLIOGRAFÍA}

FMI http://www.imf.org BIDhttp://www.iadb.org OCDEhttp://www.oecd.org

Ing. MBA Wilmer Iván Cloud Miraval, profesor del EPEL - URP, Gerente General en Marketing Directo Consulting SAC. Ha laborado en "El Comercio", "Telefónica del Perú", "BASA", "Pizza Hut".

Twitter:@cloud_ivan

Linkedin: http://www.linkedin.com/profile/view?id=146830324\&trk=tab_pro 
